\title{
Mechanistic studies on the free radical decomposition of some oxalic acid arylhydrazides: a source of aryl radicals in aqueous solution
}

\author{
Bruce C Gilbert, *a Petre Ionita, ${ }^{a}$ John R Lindsay Smith, ${ }^{* a}$ John Oakes ${ }^{b}$ and Niels \\ Ouwerkerk $^{\mathrm{c}}$ \\ ${ }^{a}$ University of York, Department of Chemistry, York, UK YO1 5DD \\ ${ }^{b}$ Unilever Research, Port Sunlight laboratories, Bebington, Merseyside, UK L63 3JW \\ ${ }^{c}$ Unilever R\&D, Olivier van Noortlan 120,Postbus 114,NL 3130 AC Vlaardingen, \\ The Netherlands \\ E-mail: bcg1@york.ac.uk
}

\begin{abstract}
UV-Vis, ${ }^{1} \mathrm{H}$ NMR and EPR (with spin-trapping) spectroscopy, MS and product studies have been used to study the reactions of dihydrazide and monohydrazide esters of oxalic acid in aqueous base $(\mathrm{pH}$ 10.5). In the absence of dioxygen, the dihydrazides are stable although the monohydrazide esters are rapidly hydrolysed in a reaction that gives monohydrazide oxalate anions, but not aryl radicals. However, in contrast both types of compound are rapidly degraded by dioxygen to give aryl radicals. The mechanisms involve an initial oxidation of the hydrazide anion by dioxygen followed by hydrolysis to give the corresponding aryl diazene anion. Further oxidation and loss of nitrogen yields aryl radicals. A mechanistic reaction scheme is proposed to account for the role of dioxygen, the fate of the aryl radicals and the products formed. The scope of these reactions as a non-photochemical source of aryl radicals under mild conditions is considered.
\end{abstract}

Keywords: Aryl radicals, mono-arylhydrazides, di-(arylhydrazides), oxidation, dioxygen

\section{Introduction}

Despite their reported carcinogenicity, ${ }^{1}$ hydrazines and their hydrazide derivatives have been widely used as synthetic intermediates in industry and as therapeutic agents for the treatment of depression, cancer, hypertension and Parkinson's disease. ${ }^{2}$ The dominant metabolic pathway normally involves their ready oxidation ${ }^{3}$ which leads, by the loss of nitrogen, to the generation of free radicals that cause cellular damage, including covalent bonding to protein and DNA molecules. ${ }^{4}$ Thus phenylhydrazine in oxygenated biological systems generates the phenyl radical which deactivates a number of enzymes (e.g. peroxidases, ${ }^{5}$ amine oxidases ${ }^{6}$ and papain ${ }^{7}$ ) and is a 
haemolytic poison. ${ }^{8}$ Reaction of phenylhydrazine with dioxygen also leads to the superoxide radical and hydrogen peroxide, both of which contribute further to cellular damage. ${ }^{2 c, 9,10}$

The enzymic oxidation of phenylhydrazine has been applied to mapping the topology of the active sites in haem proteins. ${ }^{11-16}$ These studies rely on the rapid formation phenyl radicals at the site of oxidation of phenylhydrazine. With peroxidases, ${ }^{11}$ the recovered haem shows attack by the phenyl radical on the haem edge at C20 and the C18 methyl, whereas with the other haem proteins an iron-phenyl species is formed. This suggests that access to the iron centre in peroxidases, unlike other haem systems, is restricted by the protein matrix and as a result oxidation occurs close to $\mathrm{C} 20$ and the $\mathrm{C} 18$ methyl group.

Relevant non-biological oxidation of arylhydrazine derivatives include the reactions of acyl and sulfonyl derivatives with silver(I) ions, with potential application in hydrazine-promoted "infectious" photographic development. ${ }^{17}$ (These compounds increase the speed and contrast of silver halide film during development. ${ }^{18}$ Mechanisms proposed for the oxidation of hydrazides by $\operatorname{Ag}(\mathrm{I})^{17,19}$ relate to the biological oxidations described above and involve the formation of aryl radicals, from a combination of redox and acid-base reactions, and are sensitive to the presence of air and trace metal ions. ${ }^{17}$

In this paper we describe of the autoxidation of a selection of arylhydrazides. Unlike previous studies, the majority of the substrates chosen are mono- and di-hydrazides (1a-1i, $\mathbf{2 a - 2 d}$ and 3a-3d) of the dicarboxylic acid, oxalic acid. For comparison, the oxidation of the phenylhydrazides of two monocarboxylic acid (4a and $\mathbf{4 b}$ ) and some related phenyldiazenyl compounds (5a-5e) have also been studied. Our aim was to gain an overview and an understanding of the reaction mechanisms, especially in the context of the reactions discussed above. Specifically we wished to explore the effects of structure, dioxygen, $\mathrm{pH}$ and additives [e.g. copper(II) ions] on the products of these reactions and to investigate the potential of arylhydrazine derivatives as a practicable source of aryl radicals in aqueous solution under mild conditions.

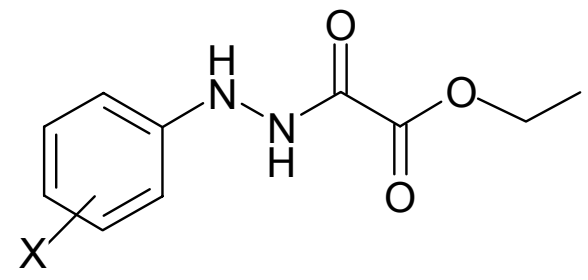
1a, $\mathrm{H}$
1b, 3-Cl
1c, $4-\mathrm{Cl}$
1d, 4-Me
1e, 4-OMe
1f, 3-OMe
$1 \mathrm{~g}, 4-\mathrm{SO}_{3} \mathrm{Na}$
$1 \mathrm{~h}, 4-\mathrm{NO}_{2}$
1i, $4-\mathrm{CO}_{2} \mathrm{H}$ 
<smiles>[X]c1ccc(NNC(=O)C(=O)NNc2ccccc2)cc1</smiles><smiles>[V]</smiles>

2a, $\mathrm{H}$

2b, 4-Me

2c, 3-Me

2d, 4- $\mathrm{CO}_{2} \mathrm{H}$<smiles>[Y]N(C(=O)C(=O)OCC)N([Y])c1ccccc1</smiles><smiles>[X]C(=O)NNc1ccccc1</smiles>

$\begin{array}{cll} & \text { X } & Y \\ \text { 3a, } & \text { Me } & \text { H } \\ \text { 3b, } & \text { H } & \text { Me } \\ \text { 3c, } & \text { Me } & \text { Me } \\ \text { 3d, } & \mathrm{Ph} & \mathrm{H} \\ \text { X } & & \end{array}$

4a, 4-MePh

4b, 4-OMePh<smiles>[X]N=Nc1ccccc1</smiles>

\section{Results and Discussion}

Initial experiments were carried out under anaerobic conditions at $\mathrm{pH} 10.5$ and subsequently repeated in the presence of air, and with added copper (II) ions. Finally, we have explored the reactions of these compounds in an organic solvent (dichloromethane) with lead dioxide as oxidant. Reactions in aqueous solution were followed by UV-Vis spectroscopy and radical intermediates were examined by spin-trapping EPR techniques and the products were characterised.

\section{The reactions of the arylhydrazides in aqueous base: UV-Vis Experiments}

a) The pH dependence of the UV-Vis spectra of arylhydrazides in aqueous solution. All the compounds were dissolved in a small amount of deoxygenated DMSO and added to deoxygenated water containing EDTA, to complex traces of transition metal ions. The $\mathrm{pH}$ of the solutions was adjusted to 7 and 10.5 and their UV-Vis spectra were recorded. For compounds 1a-1i and 2a-2d the UV-Vis spectra show a shift in $\lambda_{\max }$, from 270-280 nm at $\mathrm{pH} 7$ to $310-340$ 
$\mathrm{nm}$ at $\mathrm{pH}$ 10.5. Figure 1 shows the spectra for 1a that are typical of all these compounds. These bathochromic shifts in basic solution arise from the ionisation of the arylhydrazides (Reaction 1).
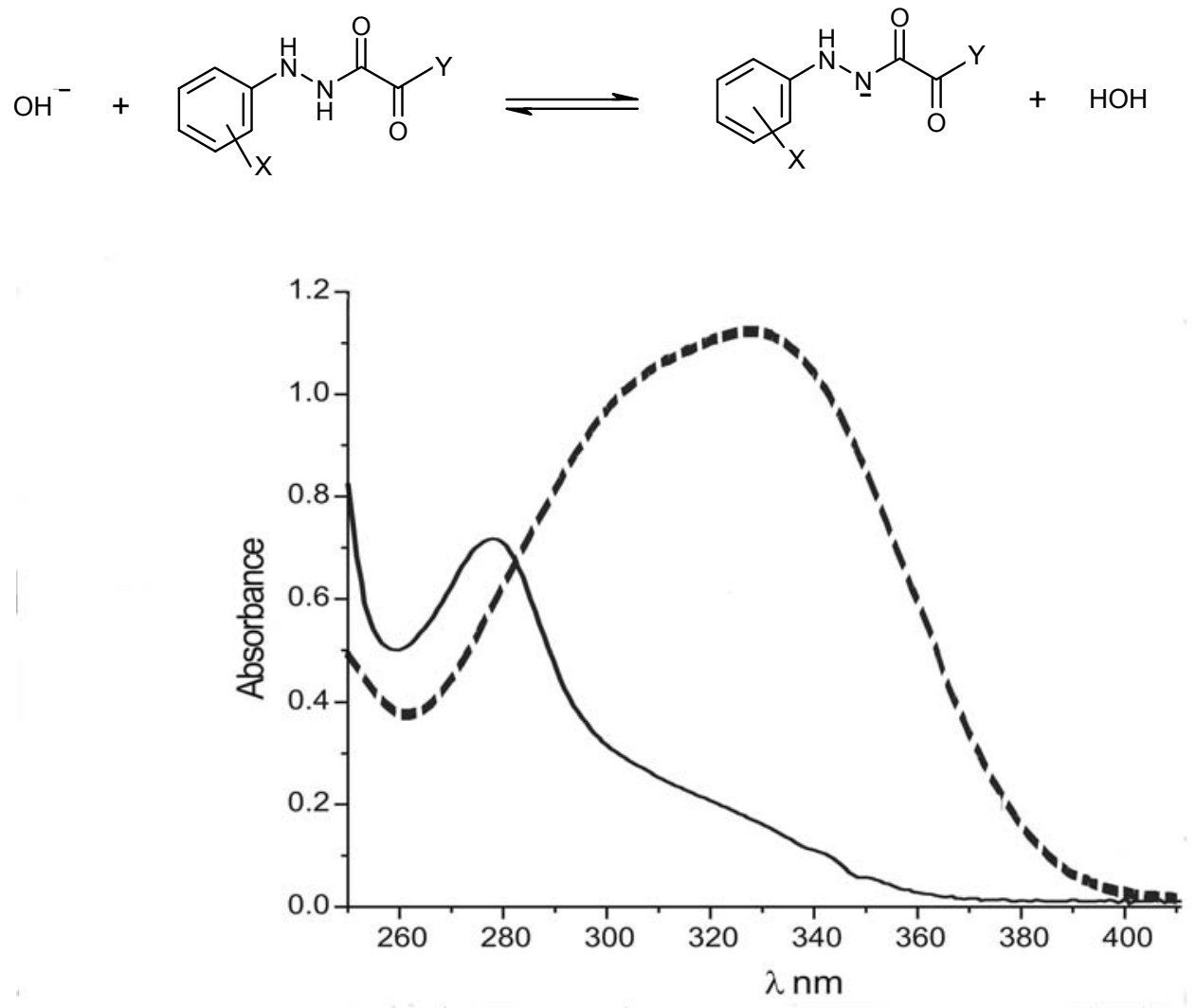

Figure 1. UV-Vis spectrum of $1 \mathbf{a}$ in aqueous solution at $\mathrm{pH} 7$ (-) and $\mathrm{pH} 10.5$ (---).

Compounds 3a-3d which have one or both of the NH protons substituted do not show the above spectral change at $\mathrm{pH}$ 10.5. This is not surprising for $\mathbf{3 b}$ and $\mathbf{3 c}$ where the proton $\alpha$ to the $\mathrm{C}=\mathrm{O}$ group is methylated but it was unexpected for $\mathbf{3 a}$ and $\mathbf{3 d}$. Presumably the $\mathrm{pK}_{\mathrm{a}}$ values of the latter two compounds are higher than that of the parent compound 1a. In agreement with this conclusion, at higher $\mathrm{pHs}(\geq 13)$ or in alcoholic base, UV-Vis spectra show both are ionised. The monocarboxylic acid phenylhydrazides, $4 \mathbf{a}$ and $\mathbf{b}$, also only ionise at $\mathrm{pHs}$ above 10.5. As expected, the spectra of compounds $\mathbf{5 a - 5 e}$ which have no $\mathrm{NH}$ protons are unaffected by changing the $\mathrm{pH}$ from 7 to 10.5 .

\section{b) Determination of $\mathbf{p} K_{\mathrm{a}}$ values for compounds $1 \mathrm{a}, \mathrm{b}$ and $2 \mathrm{a}$}

The large UV-Vis spectral change that occurs on ionisation of compounds 1a-1i and 2a-2d allows $\mathrm{pK}_{\mathrm{a}}$ measurement via the absorption spectra at different $\mathrm{pHs}$ (between 7 and 12). The $\mathrm{pK}_{\mathrm{a}}$ values obtained for three representative compounds, 1a, b and 2a, are 8.63, 8.11, and 8.50, respectively. Compounds $\mathbf{1 c}-\mathbf{1 i}$ and $\mathbf{2 b - 2 d}$ were not studied in detail but have $\mathrm{pK}_{\mathrm{a}}$ values between 8 and 9 . 


\section{c) Decomposition of compounds 1a-1i, 2a-2d, 3a-3d and 4a-4b at $\mathrm{pH} 10.5$}

In anaerobic aqueous base ( $\mathrm{pH} 10.5$ ), compounds $\mathbf{1 a - 1 i}$ are ionised and decompose in $\sim 30 \mathrm{~min}$. In contrast, compounds $\mathbf{2 a - 2 d}$ which are also ionised are stable. Multi-wavelength UV-Vis monitoring of the anaerobic reactions of 1a-1i shows that the disappearance of the anion absorbance at $\lambda_{\max } 310-340 \mathrm{~nm}$ is accompanied by an increase in a new absorbance ( $\lambda_{\max } 270$ $280 \mathrm{~nm}$ ) of the hydrolysis product, monoarylhydrazide oxalate anion, (see below). The introduction of air at the end of the anaerobic reaction did not lead to any further spectral changes. The phenylhydrazides 3a-3d, $\mathbf{4 a}$ and $\mathbf{4 b}$ are not ionised in aqueous base, $\mathrm{pH}$ 10.5, and are stable (UV-Vis spectroscopy)

In aerobic aqueous base ( $\mathrm{pH}$ 10.5), the anions of compounds 1a-1i decompose at a comparable rate to the corresponding reactions under nitrogen. Interestingly, under these conditions, in striking contrast to their anaerobic stability, compounds 2a-2d also react: after an initial slower phase they decompose as rapidly as 1a-1i. The phenylhydrazides $\mathbf{3 a - 3 d}, \mathbf{4 a}$ and $\mathbf{4 b}$, however, remain unreactive. UV-Vis monitoring of the aerobic reactions of $\mathbf{1 a - 1 i}$ and $\mathbf{2 a - 2 d}$ (see for example 1a, Figure 2), shows the disappearance of the hydrazide anion $\left(\lambda_{\max } 310-340 \mathrm{~nm}\right)$, the appearance of an intermediate $\left(\lambda_{\max } 270 \mathrm{~nm}\right)$ and finally the formation of stable products (including arylazo compounds) absorbing in the UV and at $420 \mathrm{~nm}$. The above intermediate, which is distinct from the product with a similar absorbance formed in the anaerobic reactions, reaches a maximum concentration at the point where the decomposition of the anion is complete.

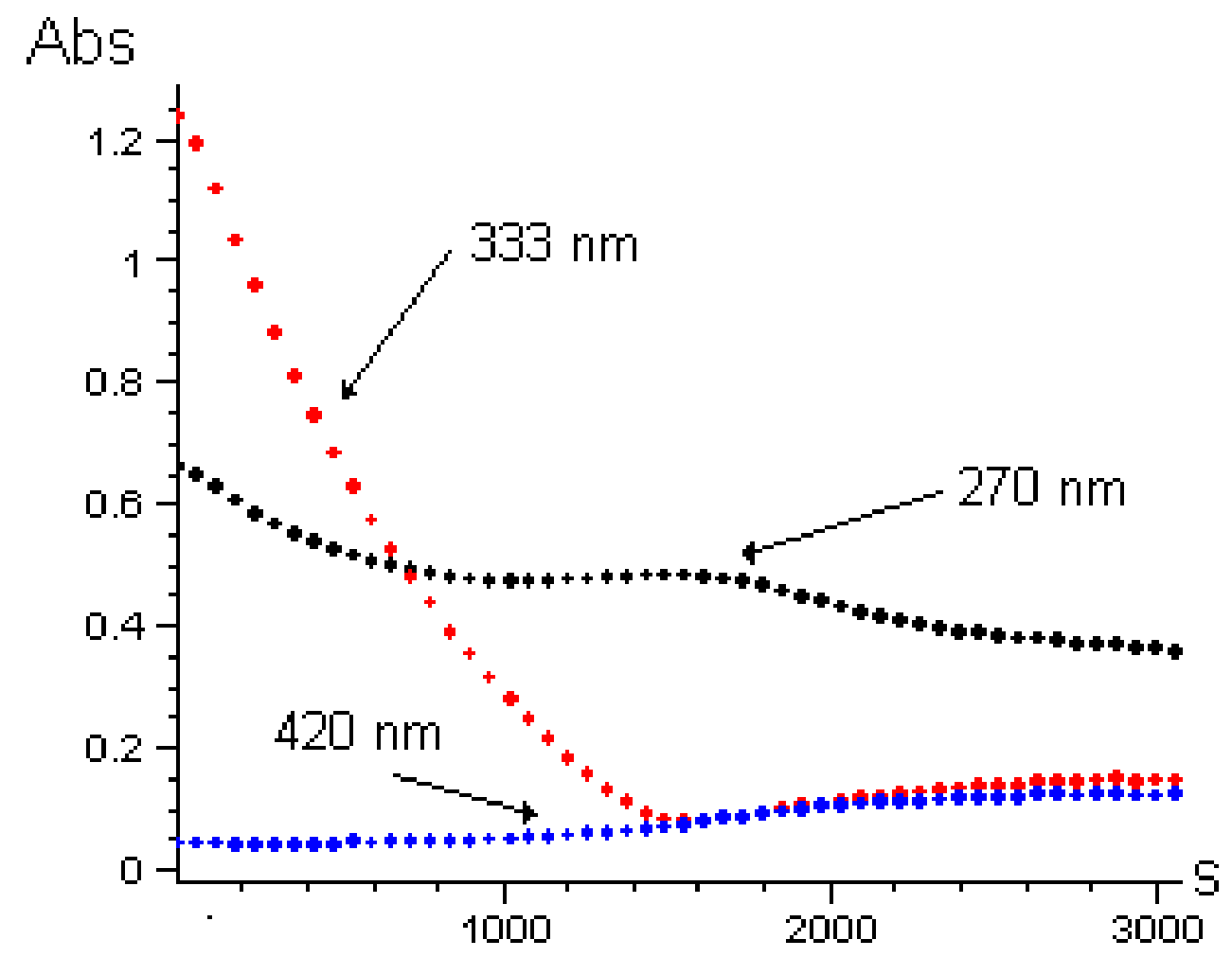

Figure 2. Decomposition of $1 \mathrm{a}$ in aerobic aqueous base ( $\mathrm{pH} 10.5)$ followed at three wavelengths, 270,333 and $420 \mathrm{~nm}$. 
The addition of the oxidants $\mathrm{H}_{2} \mathrm{O}_{2}$ and $\mathrm{KO}_{2}$ to the aerobic reactions of $\mathbf{2 a - 2 d}$ eliminates the slow phase (see for example Figure 3) and leads to a marked increase in the overall rate of reaction. Presumably the additives either speed up the generation of radicals or, in the case of $\mathrm{H}_{2} \mathrm{O}_{2}$, the strongly nucleophilic $\mathrm{HO}_{2}{ }^{-}$anion may increase the rate of hydrolysis.

Decreasing the $\mathrm{pH}$ of the aerobic reactions leads to a decrease in the rate of decomposition of the hydrazides 1a-1i and $\mathbf{2 a - 2 d}$ and below pH 7.5 the compounds are significantly more stable. This suggests the involvement of the hydrazide anions and/or hydroxide ion in the oxidative/hydrolytic degradations, in agreement with the conclusions of Bowman et al. ${ }^{17 \mathrm{~d}}$ on the mechanism of hydrazide-induced 'infectious development'.

Interestingly, all the phenyl diazene derivatives 5a-5e, even though they are not ionised, decompose rapidly in aqueous base (see mechanistic discussion below).

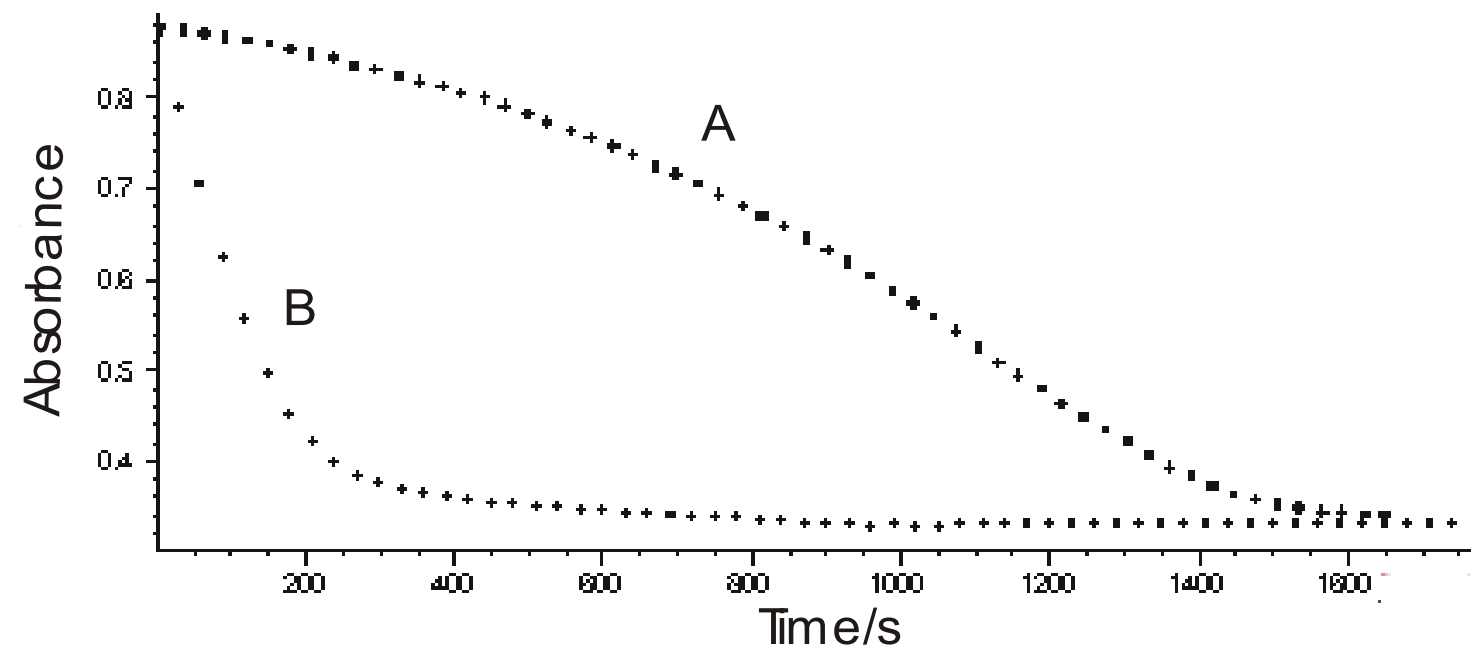

Figure 3. Decomposition of $\mathbf{2 a}$ in aerobic aqueous base (pH 10.5) followed at $333 \mathrm{~nm}$, (A) in the absence and (B) in the presence of $\mathrm{KO}_{2}$.

\section{d) The influence of copper(II) ions and EDTA}

The addition of copper(II) ions (10\% relative to substrate) to the aerobic reactions of compounds 1a-1i and 2a-2d was found to increase dramatically the rate of reaction (see for example Figure 4). The presence of EDTA in the reactions with copper(II) ions, was found to remove the rate enhancing effect and restore the reaction profiles to those described in section 1c above. These experiments show that, analogous to the silver(I) oxidation of $N$-formyl-, $N$-acetyl- and $N$ benzoyl-aryhydrazines, ${ }^{17}$ the oxalyl hydrazines used in this study are prone to oxidative degradation by copper(II). EDTA, by complexing the copper ions, exclusively inhibits these redox processes. 


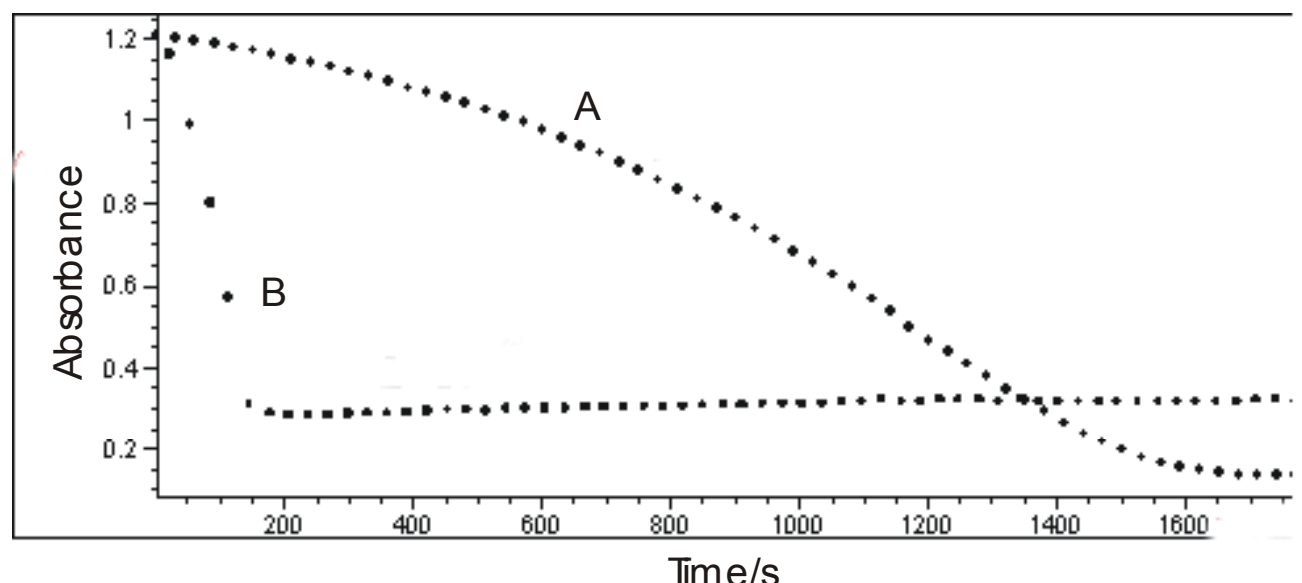

Figure 4. Decomposition of $\mathbf{2 a}$ in aerobic aqueous base $(\mathrm{pH} \mathrm{10,5)}$ followed at $333 \mathrm{~nm},(\mathbf{A})$ in the absence and (B) in the presence of $\mathrm{Cu}^{2+}$.

\section{EPR experiments}

The involvement of free radicals in the decomposition of hydrazides 1a-1i was investigated by EPR spectroscopy using the spin-traps $N$-t-butylphenylnitrone (PBN, 6), 5,5-dimethyl-1pyrroline $\mathrm{N}$-oxide (DMPO, 7) and its phosphorylated derivative (DEPMPO, 8), as well as 2methyl-2-nitrosopropane (MNP, 9). These were chosen for their ability to provide diagnostic information on a range of radicals and, in the case of MNP, because the splitting patterns of the spin-adducts can be used to differentiate between carbon-centred radicals. ${ }^{20}$ The spin-traps PBN, DMPO and MNP have been used previously to detect aryl radicals in the copper(II) initiated aerobic oxidation of phenylhydrazine, ${ }^{10 a}$ during phenylhydrazine induced haemolysis ${ }^{10}$ and infectious development with $N$-formyl-, $N$-acetyl- and $N$-benzoyl-hydrazines. ${ }^{17 b, 17 c, 21}$

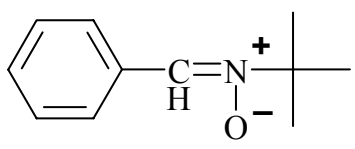

$\operatorname{PBN}(6)$

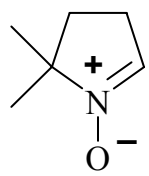

DMPO (7)

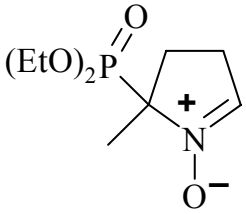

DEPMPO (8)

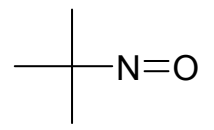

MNP (9)

The anaerobic reactions of compounds $\mathbf{1 a - 1 i}$ and $\mathbf{2 a - 2 d}$, in the presence of the nitrone traps PBN, DMPO and DEPMPO, gave very low intensity EPR spectra of spin-adducts, with the same parameters as the adducts formed in aerobic reactions (see below), which built up over the 30 min reaction times. It is probable that these arise from radicals generated by autoxidation by traces of dioxygen present in the reactions rather than from the hydrolytic reactions. The presence of copper(II) in the systems increased the intensity of the EPR signals.

Adding the nitrone spin-traps to aerobic basic aqueous solutions of 1a, 2a and 5a-5e gave strong EPR signals with values of $a_{N}, a_{H}$ and, for DEPMPO, $a_{P}$ shown in Table 1 (see also Figure 
5). These parameters are typical of phenyl radical adducts in each case ${ }^{20}$ (see below). Similar EPR spectra were also obtained for $\mathbf{1 b}-\mathbf{1} \mathbf{i}$ and $\mathbf{2 b - 2 d}$. (The remoteness of the aryl substituent from the nitroxide centre provides an explanation for the invariance of the splittings). Addition of EDTA had no effect on the intensity of the spectra suggesting that the radicals observed are not generated by catalysis by traces of transition metal ions. On the other hand, addition of copper(II) ions boosted the intensity of the signals leading to the conclusion that metal-catalysed oxidative degradation of the hydrazides can be achieved.
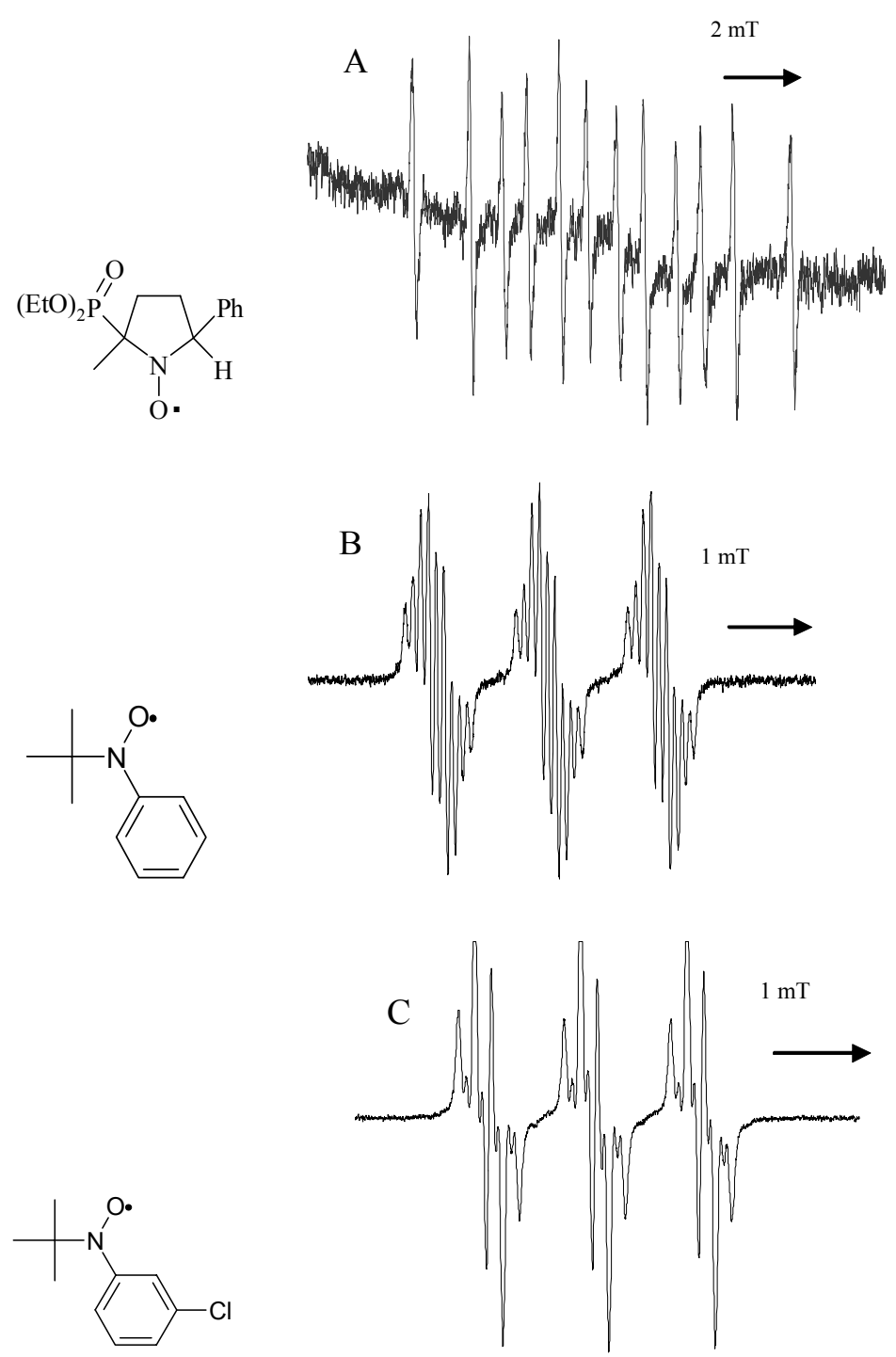

Figure 5. EPR spectra of nitroxides formed by aryl-radical addition to spin-traps (for structure and splitting constants see Table 1); (A) spin-adduct from the phenyl radical, formed from reaction of 5a in aerobic aqueous base $(\mathrm{pH} \mathrm{10.5)}$ and spin trap DEPMPO 8; (B) spin-adduct formed by the reaction of the phenyl radical, obtained by oxidation of 1 a with $\mathrm{PbO}_{2}$ in $\mathrm{DCM}$, with MNP 9; (C) spin-adduct formed by the reaction of the 3-chlorophenyl radical, obtained by oxidation of $\mathbf{1 b}$ with $\mathrm{PbO}_{2}$ in DCM, with MNP 9. 
We attempted to differentiate spectroscopically between the substituted aryl radicals in aqueous solution by the use of the nitroso trap MNP, but its low solubility in the basic aqueous solution led to the failure to obtain EPR signals. We therefore oxidised substrates 1a-1i, 2a-2d and $\mathbf{4 a - 4 b}$ in dichloromethane with lead dioxide. Signals attributed to aryl radical adducts were again observed for the nitrone spin traps (see Table 1). Strong signals were also obtained in the presence of the spin trap MNP attributed to the appropriate aryl radicals, each showing characteristic ring-proton splittings which confirm the assignments.

Table 1. EPR Hyperfine Splittings for Nitroxide spin adducts detected in the oxidation of aryl hydrazides

\begin{tabular}{|c|c|c|c|c|}
\hline Compound & $1 \mathrm{a}, 2 \mathrm{a}, 5 \mathrm{a}-\mathrm{e}$ & $1 \mathrm{a}, 2 \mathrm{a}, 5 \mathrm{a}-\mathrm{e}$ & $1 \mathrm{a}, 2 \mathrm{a}, 5 \mathrm{a}-\mathrm{e}$ & $1 \mathrm{a} 2 \mathrm{a}$ \\
\hline $\begin{array}{l}\text { Solvent/ } \\
\text { Oxidant }\end{array}$ & Water/air & Water/air & Water/air & $\mathrm{DCM} / \mathrm{PbO}_{2}$ \\
\hline Spin-trap & 6 & 7 & & 6 \\
\hline Spin-adduct & $\mathrm{Ph}$ & & $\mathrm{O}$ & $\mathrm{Ph} \mathrm{O}$. \\
\hline \multicolumn{5}{|l|}{$\begin{array}{c}\text { Hyperfine } \\
\text { Splittings } / \mathrm{mT}^{\mathrm{a}}\end{array}$} \\
\hline $\mathrm{a}_{\mathrm{N}}$ & 15.70 & 14.13 & 14.46 & 14.86 \\
\hline$a_{H}$ & 4.02 & 20.50 & 22.67 & 2.54 \\
\hline$a_{P}$ & - & - & 45.34 & - \\
\hline
\end{tabular}

\section{Table 1. (Continued)}

\begin{tabular}{|c|c|c|c|c|c|}
\hline Compound & $1 \mathrm{a} 2 \mathrm{a}$ & $1 \mathrm{a} 2 \mathrm{a}$ & $1 \mathrm{a} 2 \mathrm{a}$ & $1 \mathrm{~b}$ & $1 \mathrm{c}$ \\
\hline Solvent/Oxidant & $\mathrm{DCM} / \mathrm{PbO} 2$ & $\mathrm{DCM} / \mathrm{PbO} 2$ & $\mathrm{DCM} / \mathrm{PbO} 2$ & $\mathrm{DCM} / \mathrm{PbO} 2$ & $\mathrm{DCM} / \mathrm{PbO} 2$ \\
\hline Spin-trap & 7 & 8 & 9 & 9 & 9 \\
\hline & \multicolumn{5}{|c|}{ Spin-adduct } \\
\hline \multicolumn{6}{|l|}{ Hyperfine } \\
\hline \multicolumn{6}{|l|}{ Splittings/mTa } \\
\hline $\mathrm{aN}$ & 13.92 & 13.95 & 13.16 & 12.63 & 12.75 \\
\hline \multirow{2}{*}{$\mathrm{aH}$} & \multirow{2}{*}{19.22} & \multirow{2}{*}{20.94} & $1.82(o, p)$ & $1.92(\mathrm{o}, \mathrm{p})$ & $2.02(\mathrm{o})$ \\
\hline & & & $0.87(\mathrm{~m})$ & $0.81(\mathrm{~m})$ & $0.92(\mathrm{~m})$ \\
\hline $\mathrm{aP}$ & - & 45.00 & - & - & - \\
\hline
\end{tabular}

${ }^{\mathrm{a}} \pm 0.05 \mathrm{mT}$ 
Compounds 3a-3c gave no detectable radicals and 3d, when subjected to oxidation with lead dioxide in dichloromethane, gave a persistent radical $\left(\mathrm{a}_{\mathrm{N} 1} 9.0 \mathrm{G}, \mathrm{a}_{\mathrm{N} 2} 8.78 \mathrm{G}, \mathrm{a}_{\mathrm{Ho}, \mathrm{p}} 1.78 \mathrm{G}\right.$ and $\mathrm{a}_{\mathrm{Hm}}$ $0.82 \mathrm{G}$ ) which has been assigned to the sterically hindered radical $\mathbf{1 0}$.

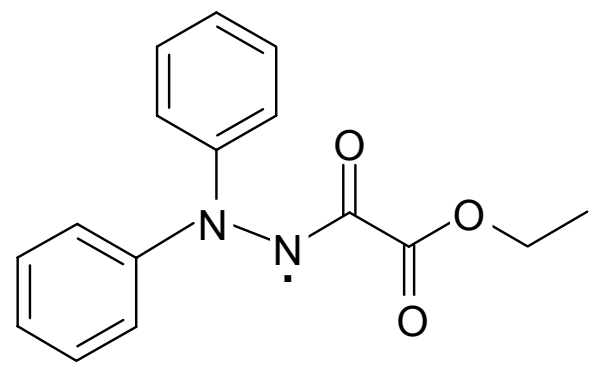

10

\section{Product studies}

(a) Anaerobic reactions. ${ }^{1} \mathrm{H}$ NMR analyses of reactions of 1a, performed in anaerobic basic $\mathrm{D}_{2} \mathrm{O}$, show the disappearance of the anion of $\mathbf{1 a}$ and the appearance of resonances attributable to ethanol and phenylhydrazide oxalate anion, as the only detectable products from hydrolysis of the hydrazide ester. GC-MS Analyses of the anaerobic reaction mixtures of 1a-1i also reveal trace products from the corresponding aryl radical (e.g. the parent aromatic compound and biaryls). For compound $\mathbf{1 b}$, these are chlorobenzene and three isomeric dichlorobiphenyls. It is likely that these products arise from air oxidation during work-up for the GC-MS analyses rather than from the anaerobic reactions themselves (see below). The addition of copper(II) to the anaerobic reactions leads to an increase in the yields of these products from the aryl radicals and to anilines.

(b) Aerobic reactions. ${ }^{1} \mathrm{H}$ NMR experiments, performed with $1 \mathrm{a}$ in aerobic, basic $\mathrm{D}_{2} \mathrm{O}$, show the decomposition of the anion and the formation of both ethanol and benzene. Other products (GC-MS analysis) include monodeuterated biphenyl (67\% deuterated), phenol and azobenzene. GC Analyses show that the aerobic reactions of 1a-1i give much higher yields of aryl radicalderived products than those carried out under nitrogen. The main product from $\mathbf{1 b}$, as representative of this class of compound, is chlorobenzene, with smaller amounts of three dichlorobiphenyl isomers and 3-chlorophenol. The presence of $\mathrm{Cu}^{2+}$ in the reaction increases the number of compounds formed; in particular, dichloroaminobiphenyls and di-(3chlorophenyl)amine are detected. When $\mathbf{1 b}$ is oxidised by $\mathrm{PbO}_{2}$ in dichloromethane, the products are very similar to those obtained from the reaction in aerobic aqueous base.

Hydrogen peroxide is also a major product from the aerobic reactions of 1a-1i. Typical yields, which are dependent on the substituent, are 0.2-0.7 mol $\mathrm{H}_{2} \mathrm{O}_{2} / \mathrm{mol}$ of substrate.

The fate of the carbonyl groups in the aerobic reactions of the hydrazides was expected to be oxalic acid and/or carbon dioxide and carbon monoxide. Oxalic acid has been confirmed as the major product by the addition of an excess of barium acetate to a completed reaction of $\mathbf{1 a}$. The precipitate of barium oxalate obtained accounts for virtually all $(>95 \%)$ of the carbonyl groups. 
Head-space GC analysis of the gases above an aerobic reaction of 1a detected $\mathrm{CO}_{2}(2-4 \%$ yield) but no CO.

The product distributions from the aerobic reactions of compounds $\mathbf{2 a - 2 d}$ are essentially the same as those from compounds 1a-1i and the hydrogen peroxide yields are 0.5-1.1 mo1 $\mathrm{H}_{2} \mathrm{O}_{2} /$ mol of substrate (equivalent to $0.25-0.55 \mathrm{~mol} \mathrm{H}_{2} \mathrm{O}_{2}$ /hydrazide group).

Compounds 3a-3d, $\mathbf{4 a}$ and $\mathbf{4 b}$ give no detectable products under the standard aerobic reaction conditions. However, compounds 5a-5e react rapidly under these conditions, as noted above, and the products (benzene, biphenyl, phenol and azobenzene) reflect the formation of the phenyl radical.

\section{Mechanism}

Our aim was to propose a unified mechanism to account for the observations made in this study, for a range of conditions and substrates, and for previously published results. It was anticipated that the results might provide a basis for a simple non-photochemical route to aryl radicals in aqueous solution. In particular there was a need to account for the following:

a) the requirement for basic conditions to bring about the degradations,

b) the hydrolytic stability of the dihydrazides compared to the monohydrazide esters in the absence of dioxygen (shown by UV-Vis and ${ }^{1} \mathrm{H}$ NMR spectroscopy); in contrast, in the presence of air both decompose rapidly,

c) the formation of aryl radicals in the aerobic but not in the anaerobic reactions,

d) the range of products formed in the aerobic and the copper(II)-catalysed aerobic reactions,

e) the similarity of the products obtained from the oxidative degradation of the monohydrazide esters and the dihydrazides, and

f) the isotopic labelling of the biphenyl obtained from the aerobic reaction of $1 \mathrm{a}$ in $\mathrm{D}_{2} \mathrm{O}$.

Our proposals are summarised in Schemes 1 and 2, which are based on the following arguments.<smiles>C=C=CC(=O)OC1CCCN(N[Al])C1=O</smiles>

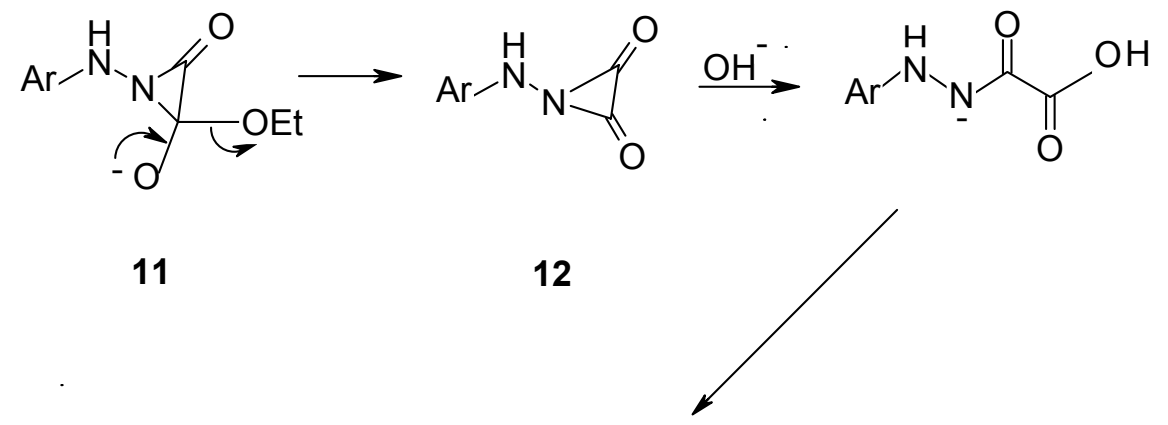<smiles>O=C([O-])C(=O)NN[Al]</smiles>

Scheme 1. Hydrolysis of oxalic acid monoarylhydrazide esters in aqueous base. 


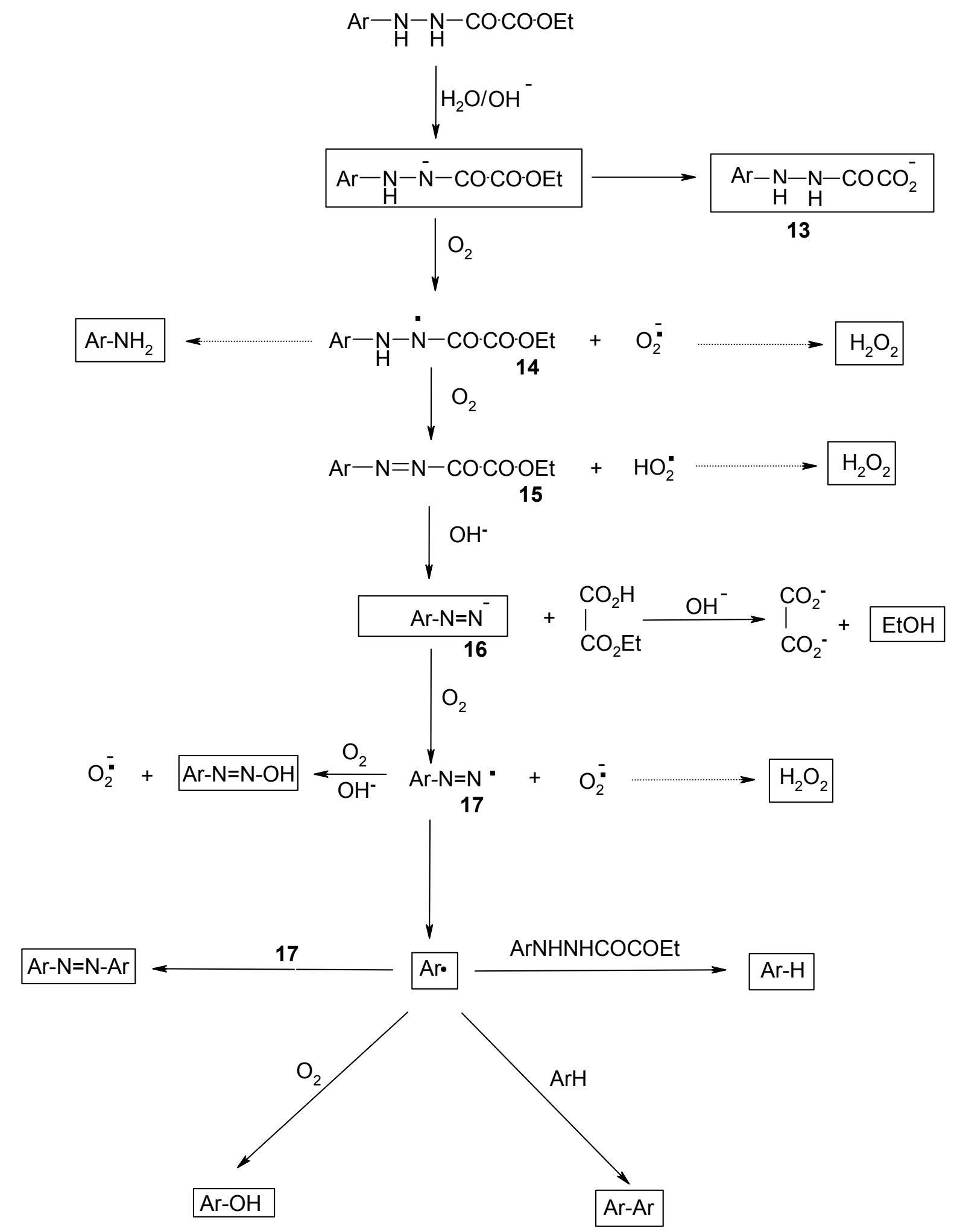

Scheme 2. Overview of reactions involved in the oxidative degradation of oxalic acid arylhydrazides in aqueous base. Compounds/intermediates in boxes have been identified in this study. 
(i) The $\mathrm{pK}_{\mathrm{a}}$ values of the oxalic acid monohydrazide esters and dihydrazides, 1a-1i and 2a2d, are between 8 and 9 so that at $\mathrm{pH} 10.5$ the $\alpha-\mathrm{NH}$ groups are extensively ionised [Reaction (1)]. As a consequence, the $\mathrm{pH}$ dependence of the aerobic reactions can be rationalised in terms of the anions being the reactive substrates. Thus, lowering the $\mathrm{pH}$ of the reactions from 10.5 to 7.5 dramatically reduces the reactivity of the compounds to aerobic oxidation. This also explains why the $N$-alkylated compounds 3a-3d and the two monocarboxylic acid phenylhydrazides, 4a and $\mathbf{4 b}$, which are less acidic $\left(\mathrm{pK}_{\mathrm{a}}>10.5\right)$, are significantly more resistant to aerobic decomposition under similar conditions. These conclusions are consistent with the hydrazide anions and not the unionised compounds being oxidised by $\operatorname{Ag}(\mathrm{I})$ in 'infectious development' (Reaction 2). ${ }^{17 \mathrm{~d}}$

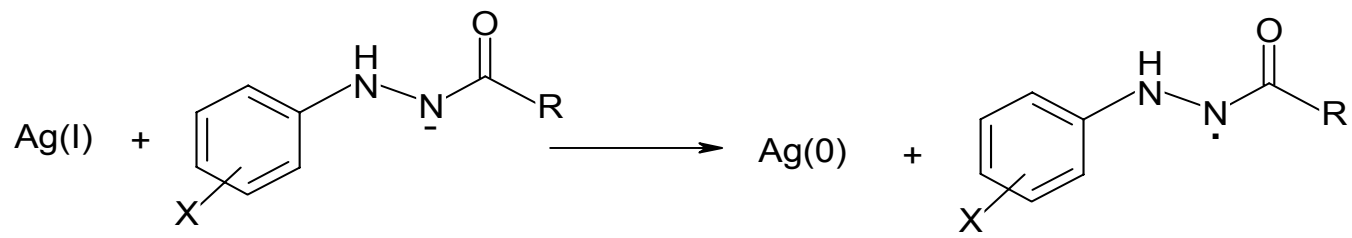

(ii) The rapid hydrolysis of the hydrazide esters 1a-1i under the anaerobic conditions is unexpected; indeed two related esters, diethyl oxalate and ethyl phenylglyoxylate, are stable to hydrolysis under the same reaction conditions. We propose that the hydrazide ester hydrolyses may involve neighbouring group participation by the hydrazide anion to form the cyclic intermediate (11), followed by loss of ethoxide to the cyclic imide (12) and subsequent reaction with hydroxide to give 13 (Scheme 1). In the comparable reaction of the anions of the dihydrazides $\mathbf{2 a - 2 d}$, the formation of $\mathbf{1 2}$ would involve the unfavourable loss of ArNHNH ${ }^{-}$from the intermediate equivalent to $\mathbf{1 1}\left(n b\right.$ the $\mathrm{pK}_{\mathrm{a}}$ values of ethanol and phenylhydrazine are $15.5^{22}$ and $c a 40,{ }^{23}$ respectively); we would expect the regeneration of the hydrazide anion to occur preferentially. We thus propose the change in the UV-Vis spectra observed in the anaerobic reactions of compounds 1a-1i (loss of $\lambda_{\max } 310-340 \mathrm{~nm}$ and formation of $\lambda_{\max } 270-280 \mathrm{~nm}$ ) arises from the hydrolysis of the hydrazide esters and formation of the monohydrazide oxalate anions (13).

(iii) The initial steps in the aerobic oxidations of compounds $\mathbf{1 a - 1 i}$ and $\mathbf{2 a - 2 d}$, are believed to involve electron transfer between dioxygen and the substrate anion to give the hydrazide radical 14 and (undetected) superoxide anion radical (Scheme 2), followed by further reaction with dioxygen to form the oxalyldiazene 15. Acylaryldiazenes are known to be rapidly solvolysed by aqueous or alcoholic base to aryldiazene anions ${ }^{17 \mathrm{~d}, 24}$ and it is likely that, once formed, intermediate $\mathbf{1 5}$ is converted to the corresponding aryldiazene anion $\mathbf{1 6}$ and monoethyl oxalate (Reaction 3 and Scheme 2). The latter is subsequently hydrolysed further to ethanol (detected by $1 \mathrm{H}$ NMR spectroscopy) and oxalate dianion (quantified with barium acetate). 


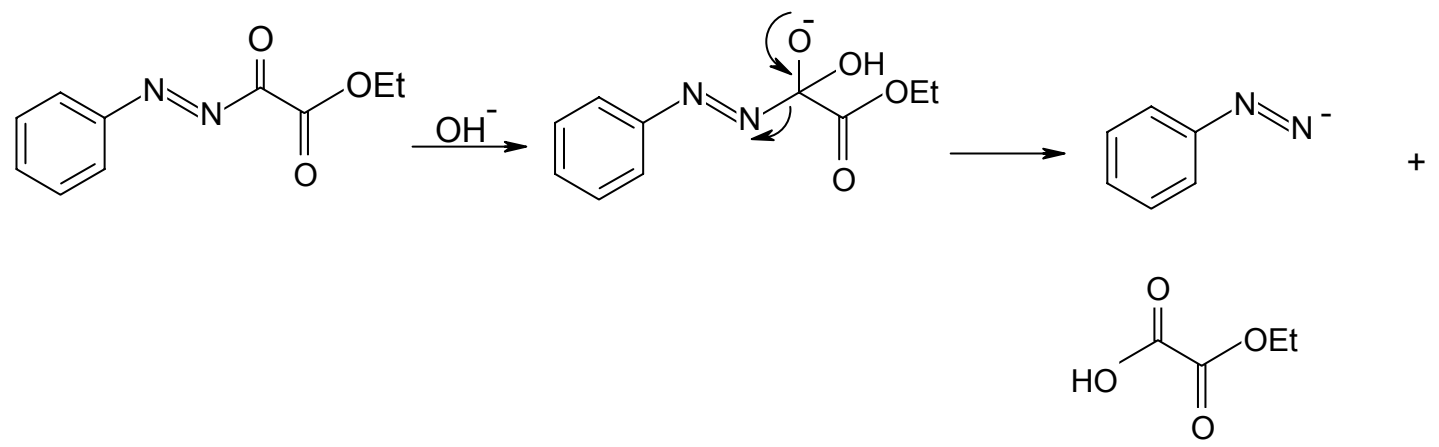

(iv) The similarity of the EPR spectra and products obtained from the reactions of compounds 1a, $\mathbf{2 a}$ and $\mathbf{5 a - 5 d}$ in the aqueous aerobic base supports the conclusion that each reacts via the common intermediates, the aryldiazene anion 16, Ar = phenyl, and the phenyl radical (Scheme 3). Although 16 could lose nitrogen to give an aryl anion ${ }^{25}$ which would form the detected parent aromatic compound (Reaction 4), the known chemistry of arydiazenes ${ }^{26}$ suggests that intermediate $\mathbf{1 6}$ will be very rapidly oxidised by dioxygen to the aryldiazenyl radical 17 which will breakdown further to aryl radicals and nitrogen. This is reflected in the products obtained (Scheme 2). The alternative oxidation of $\mathbf{1 6}$ to an aryl diazonium ion ${ }^{10 b, 26}$ cannot be a major pathway in these aerobic reactions (see below).<smiles>[R]C(=O)/N=N/c1ccccc1</smiles>

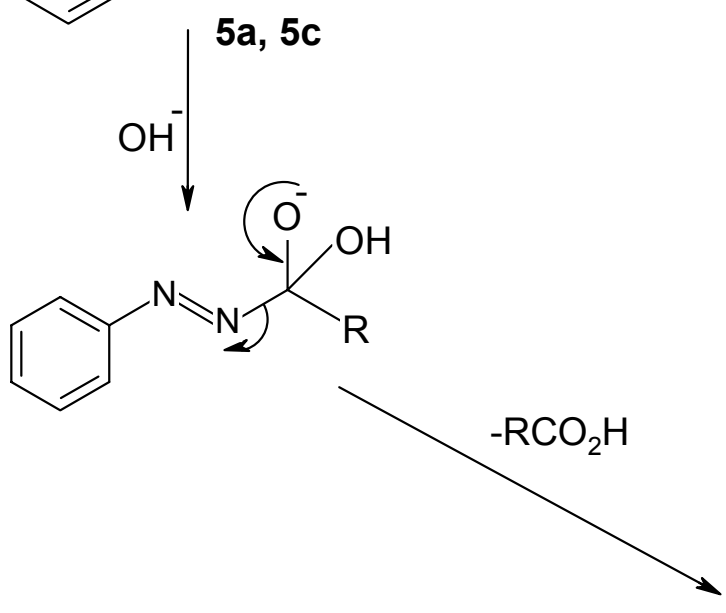

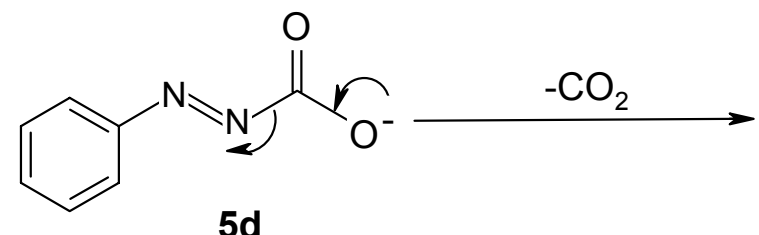<smiles>O=S(=O)(/N=N/c1ccccc1)c1ccccc1</smiles><smiles>CC=CC(=O)N=Nc1ccccc1</smiles><smiles>N#Cc1ccccc1</smiles>

Scheme 3. Oxidative hydrolysis of acyl and sulfonyl aryldiazenes to aryl radicals. 


$$
\mathrm{ArN}=\mathrm{N}^{-} \longrightarrow \mathrm{Ar}^{-}+\mathrm{N}_{2} \stackrel{\mathrm{H}_{2} \mathrm{O} / \mathrm{OH}^{-}}{\longrightarrow} \mathrm{ArH}
$$

(v) In the presence of added $\mathrm{Cu}$ (II) ions, we conclude that these reactions are catalysed by the $\mathrm{Cu}(\mathrm{II}) / \mathrm{Cu}(\mathrm{I})$ redox system in an analogous manner to the $\mathrm{Ag}(\mathrm{I})$-catalysed oxidations in 'infectious development'. ${ }^{\text {' } \mathrm{d}}$ It is also probable that copper catalyses the oxidation of $\mathbf{1 6}$ to the aryl diazonium ion accounting for some of the extra products detected (arylamines and aminobiaryls) and for the increased yield of phenols. Thus reaction of the aryl diazonium ion with the anion of the hydrazide, would give intermediate $\mathbf{1 8}$ and by subsequent hydrolysis the tetrazene, 19 (Scheme 4). Homolysis of 19 to the aminyl radical ${ }^{27}$ would lead to arylamines and aminobiaryls, 20.

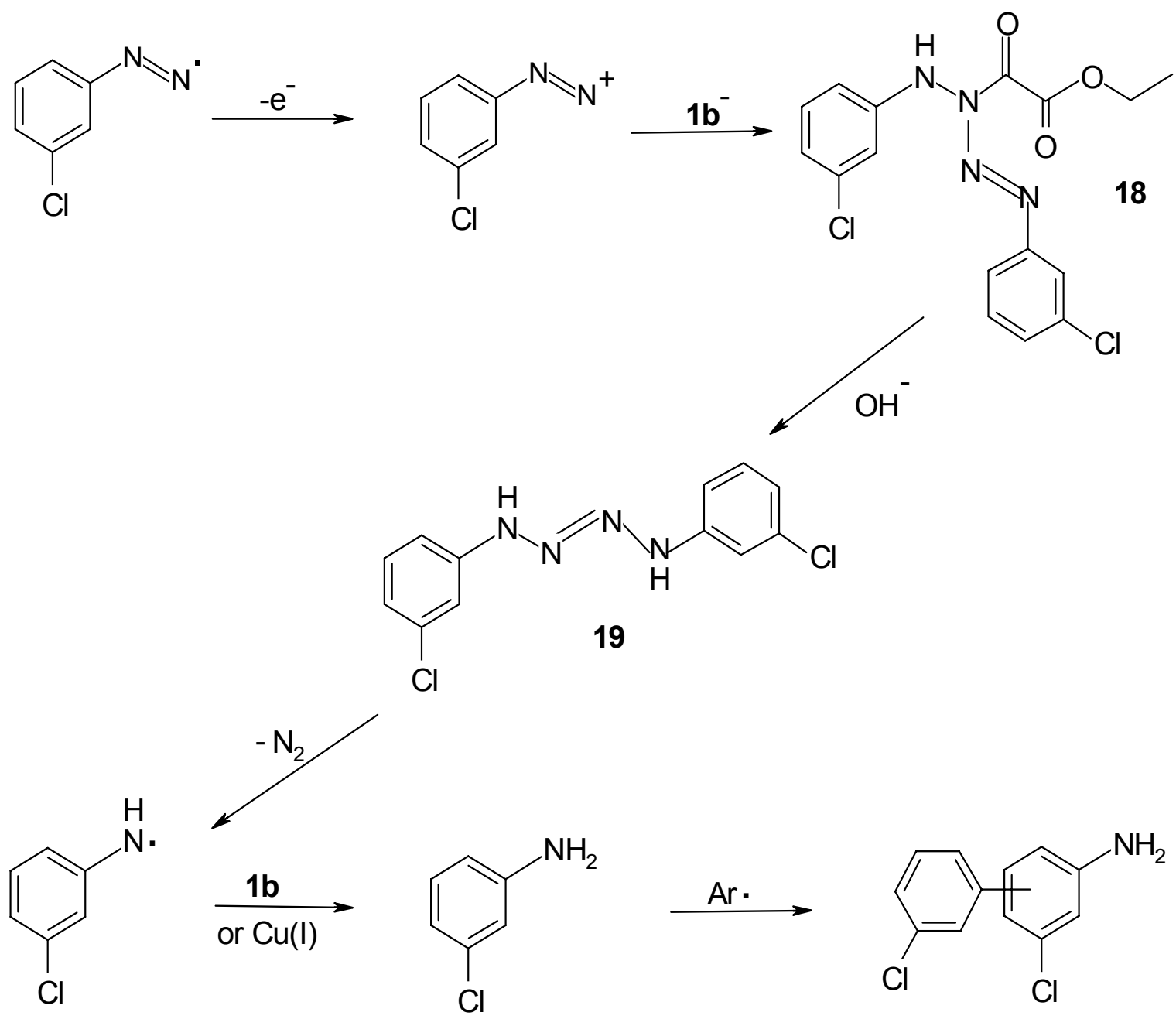

20

Scheme 4. Products arising from the oxidation of the 3-chorophenyldiazene radical to the 3chlorophenyldiazonium ion. 
A possible route to diarylamines in the copper-catalysed reactions involves oxidation of the monoarylhydrazide esters to the $N, N$-diarylhydrazide esters $(n . b$. the literature synthesis of $\mathbf{3 d}$ from $\mathbf{1 a}^{28}$ ). These, by analogy with the mechanism in Scheme 2, are oxidatively hydrolysed to azamines, 21 which are known to dimerise to tetraaryltetrazenes. ${ }^{29}$ Subsequent homolysis gives diarylaminyl radicals and diarylamines. ${ }^{27}$

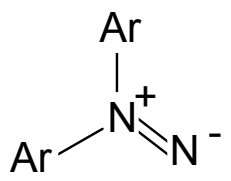

21

(vi) The main reaction of the aryl radicals, generated in Scheme 2, is hydrogen-atom abstraction from the NH groups of the hydrazide substrate to form hydrazide radicals $\mathbf{1 4}$ and the parent aromatic compound. In 'infectious development' this reaction is known as 'feedback inhibition' since it inhibits the development, by competing with the $\operatorname{Ag}(\mathrm{I})$ to $\operatorname{Ag}(0)$ reduction. Interestingly the feedback inhibition can be prevented by the addition of an alternative source of hydrogen atoms for the phenyl radicals, such as alcohols and amino alcohols. ${ }^{17 b, 30}$

(vii) Biaryls, corresponding to the aryl group in the arylhydrazide substrate, are minor products in all the reactions studied here. That these are mainly formed by arylation of the parent aromatic compound was confirmed by GC-MS analysis of the biphenyl from compound 1a in aerobic basic $\mathrm{D}_{2} \mathrm{O}$. Under these conditions the $\mathrm{NH}$ groups in 1a are exchanged for ND and the feedback inhibition mechanism yields monodeuterobenzene which reacts further to give the monodeuterobiphenyl detected. Other products derived from the aryl radicals include phenols and azo compounds from reaction with dioxygen and diazenyl radicals, respectively (Scheme 2). The azo compound $\left(\lambda_{\max } 420 \mathrm{~nm}\right)$ is not detected in the anaerobic reactions in the absence of copper(II) since aryl radicals are not generated under these conditions.

(viii) The major role of dioxygen in the aerobic reactions of 1a-1i is in the oxidation of the hydrazide anions to an oxalyldiazenes $\mathbf{1 5}$ and in the generation of aryl radicals from the aryldiazenes 16. To a minor extent it is also consumed in the oxidation of aryl radicals to give phenols (Scheme 1). The major reactions lead to the formation of superoxide/superoxide anion radicals that react further by disproportionation and/or reduction to give $\mathrm{H}_{2} \mathrm{O}_{2}$.

\section{Conclusions}

Studies using a variety of reagents, conditions and methods provide a consistent overview (Scheme 2) of mechanisms relating to the reactions of oxalic acid hydrazides in basic, aqueous solution. 
Thus the rapid hydrolysis of oxalic acid arylhydrazide esters, under nitrogen, at $\mathrm{pH} 10.5$ is attributed to substrate ionisation and anchimeric assistance by the anions, a route that is not favoured for the diarylhydrazides. However, in aerobic conditions both the mono- and diarylhydrazide anions are rapidly dehydrogenated by dioxygen to the corresponding diazenyl compounds in two sequential one-electron oxidations. The diazenyl derivatives are readily hydrolysed to aryldiazenes and, under the mild reaction conditions, these undergo further oxidation (by dioxygen) followed by loss of nitrogen to give high yields of aryl radicals.

Dioxygen is reduced to superoxide anion radical which, by disproportionation, gives hydrogen peroxide. The maximum yield of $\mathrm{H}_{2} \mathrm{O}_{2}$ predicted by Scheme 1 is 1.5 mol per hydrazide group. That this value is significantly greater than the measured values, $0.2-0.7 \mathrm{~mol} \mathrm{H}_{2} \mathrm{O}_{2}$ per hydrazide group, is due mainly to hydrogen atom abstraction from the substrate by the aryl radicals (feedback inhibition, the dominant reaction of the aryl radicals) and also in part to the consumption of hydrogen peroxide in redox processes. The sequence of dioxygen oxidations is similar to that proposed for the haem-catalysed oxidation of phenylhydrazine in biological systems, where hydrogen peroxide contributes to the cytotoxicity of phenylhydrazine. ${ }^{31}$

Oxidising the arylhydrazide esters and diarylhydrazides with lead dioxide in dichloromethane also generates aryl radicals which react to give very similar products to the reactions with dioxygen in aqueous base.

Copper(II) ions catalyse the oxidations and, in aerobic aqueous base, they can divert some of the aryldiazenyl radicals to diazonium ions. The further reactions of the cationic intermediates account for the wider range of products detected in the copper(II)-catalysed reactions.

The present study shows that oxalic acid aryl hydrazides provide a new, mild nonphotochemical source of a wide range of aryl radicals, in aqueous solution. They can be readily prepared and have the distinct advantage over hydrazides of monocarboxylic acids, which have been used as infectious development agents, in that they require less basic conditions to bring about their oxidative degradation.

\section{Experimental Section}

General Procedures. UV-Vis spectra were recorded on a Hewlett Packard 8453 spectrophotometer and analysed using a PC running Hewlett Packard A.02.05 UV-Vis ChemStation software. Quartz cuvettes $(1 \mathrm{~cm}$ pathlength) were used at all times. EPR spectra were obtained using either a JEOL JES-RE1X or a Bruker ESP 300 spectrometer. GC analyses of the organic products were carried out using a Varian 3380 gas chromatograph equipped with a flame ionisation detector and a Supelcowax 10 capillary column $(30 \mathrm{mx} 0.25 \mathrm{~mm}, 0.25 \mu \mathrm{m}$ film thickness). Carbon dioxide and carbon monoxide were quantified by GC with a Pye Unicam PU4500 gas chromatograph fitted with a thermal conductivity detector, a Tenax TA pre-column and a Carbosieve 5II column $(3 \mathrm{~m} \times 3 \mathrm{~mm})$. Data acquisition and manipulation were carried out on a PC with Jones Chromatography software, JCL6000 Chromatography Data System 2.0 for 
Windows. GC-MS analyses used a Hewlett Packard 5890 Series 2 gas chromatograph coupled to a VG Analytical Autospec mass spectrometer. ESI-MS spectra were recorded on a Finnegan LCQ MAT mass spectrometer. ${ }^{1} \mathrm{H}$ NMR spectra of $\mathrm{D}_{2} \mathrm{O}$ solutions were recorded on a JEOL JNM-EX270 (270 MHz) spectrometer.

Materials. Unless otherwise stated, the compounds were obtained from Aldrich or Lancaster and used without further purification. Deionised water was used for all experiments in buffered solutions. Compounds 1a - 1i, 2a - 2d, 3a and 4a were provided by Unilever Research and compounds $\mathbf{3 d}, \mathbf{4 b}, \mathbf{5 a}-\mathbf{5 d}$ were synthesised according to the literature methods ${ }^{17 \mathrm{~d}, 32}$ and their purity was checked by TLC, UV-Vis, MS and NMR analyses. The very air sensitive compound 5e was prepared following the method of Huang and Kosower ${ }^{32}$ and its formation was confirmed by UV-Vis spectroscopy.

Compounds $\mathbf{3 b}$ and $\mathbf{3 c}$ were obtained by methylation of $\mathbf{1 a}(208 \mathrm{mg})$ with methyl iodide (285 $\mathrm{mg})$ in DMSO $\left(10 \mathrm{~cm}^{3}\right)$, in the presence of anhydrous potassium carbonate $(400 \mathrm{mg})$. After stirring for two days at room temperature, the solution was filtered, acidified with dilute hydrochloric acid and extracted with dichloromethane. Solvent removal under vacuum gave a residue containing the crude products from which $\mathbf{3 b}(70 \mathrm{mg})$ and $\mathbf{3 c}(70 \mathrm{mg})$ were separated by preparative TLC (silica gel, 1,2-dichloroethane).

3b. gave a single spot with $\mathrm{R}_{\mathrm{f}} 0.22$ (silica gel, 1,2-dichloroethane); UV-Vis (methanol) $\lambda_{\max } 276$ nm; MS(EI) $222\left(M^{+}, 38 \%\right), 148(21), 121$ (100), 105 (26), 92 (57), 77 (43), 65 (25); $\delta_{\mathrm{H}}\left(\mathrm{CDCl}_{3}\right)$ $8.65(1 \mathrm{H}, \mathrm{s}), 6.8-7.3(5 \mathrm{H}, \mathrm{m}), 3.25(3 \mathrm{H}, \mathrm{s}), 4.36(2 \mathrm{H}, \mathrm{q}), 1.11(3 \mathrm{H}, \mathrm{t})$.

3c. gave a single spot with $\mathrm{R}_{\mathrm{f}} 0.38$ (silica gel, 1,2-dichloroethane); UV-Vis (methanol) $\lambda_{\max } 330$ $\mathrm{nm}$; MS(CI) $237\left(\mathrm{MH}^{+}, 100 \%\right), 135$ (12), $106(40) ; \delta_{\mathrm{H}}\left(\mathrm{CDCl}_{3}\right)$ 6.8-7.3 (5H, m), $3.1(3 \mathrm{H}, \mathrm{s}), 2.9$ $(3 \mathrm{H}, \mathrm{s}), 4.36(2 \mathrm{H}, \mathrm{q}), 1.11(3 \mathrm{H}, \mathrm{t})$.

\section{UV-Vis studies of reactions}

Aerobic reactions. The substrates were dissolved in DMSO, and an aliquot $\left(0.05 \mathrm{~cm}^{3}\right)$ to give a final concentration of $10^{-4} \mathrm{~mol} \mathrm{dm}^{-3}$ was added to $10^{-3} \mathrm{~mol} \mathrm{dm}{ }^{-3}$ EDTA in $50 \times 10^{-3} \mathrm{~mol} \mathrm{dm}^{-3}$ aqueous sodium carbonate $\left(0.95 \mathrm{~cm}^{3}\right)$ at $21{ }^{\circ} \mathrm{C}$ and the final $\mathrm{pH}$ corrected to 10.5 with hydrochloric acid.

For experiments with $\mathrm{Cu}(\mathrm{II}), \mathrm{H}_{2} \mathrm{O}_{2}$ and $\mathrm{KO}_{2}$, these were added at the start of the reaction to give a final concentration of $10^{-5} \mathrm{~mol} \mathrm{dm}^{-3}$.

Anaerobic reactions.- The majority of the anaerobic reactions were carried out as above except that all the solutions were deoxygenated, by bubbling nitrogen gas through the aqueous buffer for 15 min prior to the addition of the substrate, and the reactions were carried out in a nitrogen atmosphere. For a few reactions, the solutions were thoroughly degassed, with two freeze-thaw cycles, on a Schlenk line. 


\section{$\mathrm{pK}_{\mathrm{a}}$ Measurements}

Solutions of compounds $1 \mathbf{a}, \mathbf{1 b}$ and $\mathbf{2 a}\left(10^{-4} \mathrm{~mol} \mathrm{dm}^{-3}\right)$ were prepared in standard buffer solutions in the $\mathrm{pH}$ range $7-12$ containing $10^{-3} \mathrm{~mol} \mathrm{\textrm {dm } ^ { - 3 }}$ EDTA and their UV-Vis spectra were recorded immediately. These spectra were used to obtain the relative concentrations of the ionised and unionised species at each $\mathrm{pH}$ and subsequently the $\mathrm{pK}_{\mathrm{a}}$ values.

\section{Oxidations with $\mathrm{PbO}_{2}$ in dichloromethane}

The substrate $(10 \mathrm{mg})$ was dissolved in dichloromethane $\left(1 \mathrm{~cm}^{3}\right)$ and $\mathrm{PbO}_{2}(50 \mathrm{mg})$ was added under nitrogen. After stirring for $1 \mathrm{~min}$ the mixture was analysed by GC.

\section{EPR studies}

The experiments in aqueous solution were carried out under the conditions described above with the addition of the spin-trap $\left(10^{-3} \mathrm{~mol} \mathrm{dm}^{-3}\right)$. For the reactions in the absence of oxygen, the solution was deoxygenated with nitrogen gas for $15 \mathrm{~min}$ and the EPR tube was sealed with a flame. For reactions with lead dioxide, the oxidant was added to a solution of the substrate and spin-trap in dichloromethane. After $\sim 1$ min the EPR spectrum spectrum was recorded.

\section{GC and GC-MS studies}

For the aerobic experiments the substrates $(25 \mathrm{mg})$, dissolved in the minimum of DMSO were added to the aqueous base $\left(50 \mathrm{~cm}^{3}\right)$. After $24 \mathrm{~h}$ the solution was extracted with dichloromethane and after separation of the organic phase, the aqueous phase was acidified with hydrochloric acid and extracted again with dichloromethane. The combined organic phases were dried $\left(\mathrm{Na}_{2} \mathrm{SO}_{4}\right)$ and concentrated before being analysed by GC-MS. In the anaerobic reactions the solutions were degassed with nitrogen and the reactions were carried out under nitrogen. The work-up and analyses were as described above.

\section{Determination of hydrogen peroxide and oxalic acid}

The hydrogen peroxide formed during aerobic decompositions was quantified by iodometric titration. The oxalic acid yield at the end of the reaction was determined by adding acetic acid, until the $\mathrm{pH}$ was 5-6, followed by an excess of barium acetate and the mixture left for $1-2 \mathrm{~h}$. The precipitate formed was removed by filtration, dried and weighed.

\section{${ }^{1}$ H NMR studies}

The substrate (1a) $(10 \mathrm{mg})$ was added to $\mathrm{D}_{2} \mathrm{O}\left(1 \mathrm{~cm}^{3}\right)$ containing sodium carbonate $(20 \mathrm{mg})$ and the spectrum was recorded at selected time intervals. These reactions gave a precipitate which was dissolved in dichloromethane and analysed by GC-MS. 


\section{Acknowledgements}

P. I. gratefully acknowledges financial support from Unilever Research.

\section{References}

1. Toth, B. Cancer Res., 1975, 35, 3693.

2. Spearman, M. E.; Franck, T. G.; Moloney, S. J.; Prough, R. A. In Biological oxidation of nitrogen in Organic molecules; Gorrod, J. W.; Damani, L. A. Eds.; Ellis Horwood, 1985, Ch. 11.

3. (a) Chattaway, F. D. J. Chem. Soc. 1907, 1323 and 1908, 270. (b) Smith, P. A. S. In Openchain nitrogen compounds; Benjamin, 1966, Vol. 2, Ch. 9. (c) Misra, H. P.; Fridovich, I. Biochemistry 1976, 15, 681.

4. Nelson, S. D.; Mitchell, J. R.; Timbrell, J. A.; Snodgrass, W. R.; Corcoran, G. B. Science 1976, 193, 901. Moloney, S. J.; Prough, R. A. Rev. Biochem. Toxicol. 1983, 5, 313. Moloney, S. J.; Wiebkin, P.; Cummings, S. W.; Prough, R. A. Carcinogenesis 1985, 6, 397.

5. Hidaka, H.; Udenfriend, S. Arch. Biochem Biophys. 1970, 140, 174. Allison, W. C.; Swain, L. C.; Tracy, S. M.; Benitez, L. V. Arch. Bichem. Biophys. 1973, 155, 400.

6. Allison, W.C.; Swain, L. C. Arch. Bichem. Biophys. 1973, 155, 405.

7. Patek, D. R.; Hellerman, L. J. Biol. Chem. 1974, 249, 2373.

8. (a) Lamberg, R.; Legge, J. M. In Hematin compounds and bile pigments, Interscience, 1949, p 392. (b) Beavan, G. H.; White, J. C. Nature 1954, 173, 389. (c) Warburg, O.; Kubowitz, B. A.; Peisach, J.; Blumberg, W. E. Proc. Natl. Acad. Sci. USA 1970, 67, 1846.

9. Jain, K. J.; Hochstein, P. Biochim. Biophys. Acta 1979, 586, 128.

10. (a) Hill, H. A. O.; Thornalley, P. J. FEBS Letters 1981, 125, 235. (b) Hill, H. A. O.; Thornalley, P. J. Can. J. Chem. 1982, 60, 1528.

11. (a) Ator, M. A.; Ortiz de Montellano, P. R. J. Biol. Chem. 1987, 262, 1542. (b) Gilfoyle, D. J.; Rodriguez-Lopez, J. N.; Smith, A. T. Eur. J. Biochem. 1996, 236, 714.

12. (a) Ringe, D.; Petsko, G. A.; Kerr, D. E.; Ortiz de Montellano, P. R. Biochem. 1984, 23, 2.

(b) Swanson, B. A.; Ortiz de Montellano, P. R. J. Am. Chem. Soc., 1991, 113, 8146.

13. Ortiz de Montellano, P. R.; Kerr, D. E. J. Biol. Chem. 1983, 258, 10558.

14. (a) Jonen, H. G.; Werringloer, J.; Prough, R. A.; Estabrook, R. W. J. Biol. Chem. 1982, 257, 4404. (b) Swanson, B. A.; Halpert, J. R.; Bornheim, L. M.; Ortiz de Montellano, P. R. Arch. Biochem. Biophys. 1992, 292, 42.

15. Samokyszyn, V. M.; Ortiz de Montellano, P. R. Biochem. 1991, 30, 11646.

16. Ortiz de Montellano, P. R. Ann. Rev. Pharmacol. Toxicol. 1992, 32, 89.

17. (a) Shinohara, K.-I.; Bayer, E. J. Photographic Sci. 1987, 35, 181; (b) Chen, P.; Sun, R.-D.; Zheng, D.-S. J. Photographic Sci. 1992, 40, 118; (c) Chen, P.; Sun, R.-D.; Li, X.-H.; 
Zheng, D.-S. J. Imaging Sci. Technol. 1993, 37, 281; (d) Bowman, W. R.; Forshaw, J. A.; Hall, K. P.; Kitchin, J. P.; Mott, A. W. Tetrahedron 1996, 52, 3961.

18. Stauffer, R. E.; Smith, W. F.; Trivelli, A. P. H. J. Franklin Inst. 1944, 238, 291.

19. (a) Kitchin, J. P.; Hall, K. P.; Mott, A. W.; Marchesano, C.; Bowman, W. R. J. Photographic Sci. 1987, 35, 162. (b) Pladziewicz, J. R.; Slattum, P.; Sahyun, M. R. V. J. Imaging Sci. 1989, 33, 119. (c) Kitchin, J. P.; Hall, K. P.; Mott, A.W.; Marchesano, C.; Bowman, W. R. J. Imaging Technol. 1989, 15, 282. (d) Halland, K. P.; Mott, A. W. US Patent 4,798,780, 1989. (e) Chen, S.-L.; Ji, S.-X.; Zhu, Z.-H.; Yao, Z.-G. Dyes and Pigments 1994, 25, 101.

20. Buettner, G. R. Free Rad. Bio. Med. 1987, 3, 259.

21. Johnstone, R. A. W.; Neville, A. F.; Russell, P. J. J. Chem. Soc. B 1971, 1183.

22. Handbook of chemistry and physics, Ed.; Lide, D. R., CRC Press, $84^{\text {th }}$ Edn.; 2003, p 8.

23. Smith, P. A. S. In Derivatives of hydrazine and other hydronitrogens having $N$ - $N$ bonds, Benjamin/Cummings, 1983; p 3.

24. Cohen, S. G.; Nicholson, J. J. Org. Chem. 1965, 31, 1162.

25. (a) Bunnett, J. F.; Happer, D. A. R. J. Org. Chem. 1966, 31, 2369. (b) Bunnett, J. F.; Takayama, H. J. Am. Chem. Soc. 1968, 90, 5173.

26. Kosower, E. M., Acc. Chem. Res. 1971, 3, 193.

27. Smith, P. A. S. In Open-chain nitrogen compounds, Benjamin, 1966, Vol. 2, p 345.

28. Boelsing, T., Chem. Ber. 1892, 25, 1554.

29. (a) McBride, W. R.; Bens, E. M., J. Am. Chem. Soc. 1959, 81, 5546. (b) Abramovitch, R. A.; Davis, B. A., Chem. Rev. 1964, 64, 149. (b) Bhatnagar, I.; George, M. V. J. Org. Chem. 1968, 33, 2407.

30. Nothnagle, R. J. US Patent, 4,269,929 1980.

31. (a) Cohen, G.; Hochstein, P. Biochemistry 1964, 3, 389. (b) Cohen, G.; Hochstein, P. J. Pharmacol. Exp. Ther. 1965, 147, 139.

32. Huang, P. C.; Kosower, E. M. J. Am. Chem. Soc. 1968, 90, 2354 and 2362. 